\title{
Comparison of intranasal midazolam with intravenous diazepam for treating febrile seizures in children: prospective randomised study
}

\author{
Eli Lahat, Michael Goldman, Joseph Barr, Tzvi Bistritzer, Matithyahu Berkovitch
}

\begin{abstract}
Objective To compare the safety and efficacy of midazolam given intranasally with diazepam given intravenously in the treatment of children with prolonged febrile seizures.

Design Prospective randomised study.

Setting Paediatric emergency department in a general hospital.

Subjects 47 children aged six months to five years with prolonged febrile seizure (at least 10 minutes) during a 12 month period.

Interventions Intranasal midazolam $(0.2 \mathrm{mg} / \mathrm{kg})$ and intravenous diazepam $(0.3 \mathrm{mg} / \mathrm{kg})$.

Main outcome measures Time from arrival at hospital to starting treatment and cessation of seizures.

Results Intranasal midazolam and intravenous diazepam were equally effective. Overall, 23 of 26 seizures were controlled with midazolam and 24 out of 26 with diazepam. The mean time from arrival at hospital to starting treatment was significantly shorter in the midazolam group (3.5 (SD 1.8) minutes, 95\% confidence interval 3.3 to 3.7 ) than the diazepam group (5.5 (2.0), 5.3 to 5.7). The mean time to control of seizures was significantly sooner (6.1 (3.6), 6.3 to $6.7)$ in the midazolam group than the diazepam group (8.0 (0.5), 7.9 to 8.3). No significant side effects were observed in either group.

Conclusion Seizures were controlled more quickly with intravenous diazepam than with intranasal midazolam, although midazolam was as safe and effective as diazepam. The overall time to cessation of seizures after arrival at hospital was faster with intranasal midazolam than with intravenous diazepam. The intranasal route can possibly be used not only in medical centres but in general practice and, with appropriate instructions, by families of children with recurrent febrile seizures at home.
\end{abstract}

\section{Introduction}

Convulsions triggered by fever (febrile seizures) are the most common type of seizures in childhood, with a prevalence of 3-4\%. ${ }^{1}$ Acute onset of febrile seizures requires prompt medical attention, ventilation support, and appropriate oxygenation until they either stop spontaneously or are controlled by drugs.

Diazepam is the most widely used drug for the acute management of all types of seizures in both adults and children. ${ }^{2}$ However, it has a short duration of action, should be given intravenously or rectally (since its absorption is slow if given intramuscularly), and tends to accumulate if repeated doses are given, with the possible rare complication of brain stem depression leading to bradypnoea or even respiratory arrest. The introduction of an intravenous line may be difficult, particularly in children with generalised tonicclonic febrile seizures. ${ }^{3}$ Diazepam may also be given rectally to control seizures, which is as effective as intravenous diazepam. ${ }^{5}$ A literature review in 1990 identified only three cases of reversible respiratory depression in 843 patients with seizures. ${ }^{6}$

Midazolam, the first water soluble benzodiazepine, is widely accepted as a parenteral anxiolytic and premedicant. ${ }^{7}$ Its safety and efficacy as an anticonvulsant drug given intramuscularly have been shown in several studies in animals and humans (adults and children). ${ }^{3} 489$

Midazolam given intranasally as an anaesthetic agent has been shown to be safe and effective in children undergoing various diagnostic studies and minor surgical procedures. ${ }^{10-13}$ Intransal midazolam also suppresses epileptic activity and improves the background of electroencephalograms in children with epilepsy. ${ }^{14}$

We recently showed that intranasal midazolam is safe and effective for the management of acute seizures in children. ${ }^{15}$ In the present study, we aimed to compare midazolam given intranasally with diazepam given intravenously for the treatment of febrile seizures in children.

\section{Subjects and methods}

Our study was performed at the Pediatric Emergency Department of Assaf Harofeh Medical Center in Zerifin, Israel, a general hospital affiliated with a university. Over 12 months, all children between the ages of six months and five years who presented with febrile seizures (tonic, clonic, or tonic-clonic) lasting for at least 10 minutes were eligible for inclusion in our study. Febrile seizures were diagnosed retrospectively on the basis of clinical data (history, physical findings, and cerebrospinal fluid results). We excluded children with established intravenous lines or those who had received anticonvulsants before admission. We chose 10 minutes of ongoing motor seizure as the entry criterion, as most emergency physicians would initiate anticonvulsive treatment after that time. ${ }^{3}$ We estimated that upon arrival at the hospital children would have had seizures for at least 10 minutes as that is the least time it would take to reach the hospital from the nearest cities.

After seizures were controlled in the children, their parents were asked to sign a consent form giving permission to enrol them in our study. The hospital's ethics committee approved the study on the understanding that, because midazolam is rapidly taken up by the intranasal route, there would be no significant delay in treating patients randomised to receive this drug, and that if this treatment failed an intravenous line would immediately be introduced.

\author{
Editorial by Koren \\ Pediatric Neurology \\ Unit, Assaf Harofeh \\ Medical Center, \\ Zerifin 70300, Israel \\ Eli Lahat \\ senior clinical lecturer \\ Department of \\ Pediatrics, Assaf \\ Harofeh Medical \\ Center \\ Michael Goldman \\ tutor \\ Tzvi Bistritzer \\ senior lecturer \\ Pediatric Intensive \\ Care Unit, Assaf \\ Harofeh Medical \\ Center \\ Joseph Barr \\ lecture \\ Pediatric Clinical \\ Pharmacology Unit, \\ Assaf Harofeh \\ Medical Center \\ Matithyahu \\ Berkovitch \\ lecturer \\ Correspondence to: \\ E Lahat \\ shiri@gezernet.co.il \\ BMJ 2000;321:83-6
}


Children with febrile seizures received routine life support on admission to hospital. We randomly assigned 100 episodes of febrile seizure to treatment with either intranasal midazolam $0.2 \mathrm{mg} / \mathrm{kg}$ or intravenous diazepam $0.3 \mathrm{mg} / \mathrm{kg}$, the maximum dose being $10 \mathrm{mg}$. Randomisation was performed in advance with a random number table by a hospital pharmacist not involved in the study, and treatment allocations were sealed in opaque envelopes. Investigators were blind to these allocations.

Midazolam solution $(5 \mathrm{mg} / \mathrm{ml})$ was dripped by syringe into both nostrils in equal doses, and an intravenous line was immediately introduced. We recorded the following times: arrival at hospital, treatment with intranasal midazolam, intravenous access, cessation of seizures, and recurrence. Treatment was considered successful if the seizure ceased within five minutes. Seizures that stopped between five and 10 minutes after treatment were defined as successful but delayed control of seizure. Seizures that did not stop within 10 minutes after treatment were defined as treatment failures, and intravenous diazepam $0.3 \mathrm{mg} / \mathrm{kg}$ was given. Seizures that were controlled with midazolam or diazepam but recurred within 60 minutes were defined as recurrent seizures.

During seizure activity and for 60 minutes after control, the children were followed by continuous cardiorespiratory and pulse oximetry monitors. Vital signs were recorded every 15 minutes. During seizure activity, high flow oxygen was provided through a mask. All the children were admitted to the paediatric ward for 24 hour observation after cessation of seizures.

The results are presented as means (standard deviations) and 95\% confidence intervals for continuous data and proportions for nominal data. We compared the two groups by independent sample $t$ test or Fisher's exact test. We estimated the duration of seizure after arrival at hospital between the two groups from survival curves produced by using the KaplanMeier method and the log rank statistics.

\section{Results}

Overall, 53 children were eligible for our study. We excluded nine children owing to spontaneous cessation of seizure: five (one with bacterial meningitis) were randomised to receive intranasal midazolam, and four (one with viral meningitis) were randomised to receive intravenous diazepam (fig1).

Intranasal midazolam was given for 26 episodes of febrile seizures in 21 children and intravenous diazepam for 26 episodes in 23 children. Overall, 40 children had one seizure and four children had three recurrent seizures. On each occasion these children were rerandomised to either treatment group.

Table 1 summarises the patients' clinical characteristics. No statistically significant differences were found between the groups. Table 2 presents the results of treatment. The drugs were equally effective at stopping seizures. Overall, 23 of 26 seizures responded to initial treatment with intranasal midazolam and 24 of 26 responded to intravenous diazepam. Five treatment failures occurred, three in the midazolam group (all with upper respiratory tract infection) and two in the diazepam group. Two of the

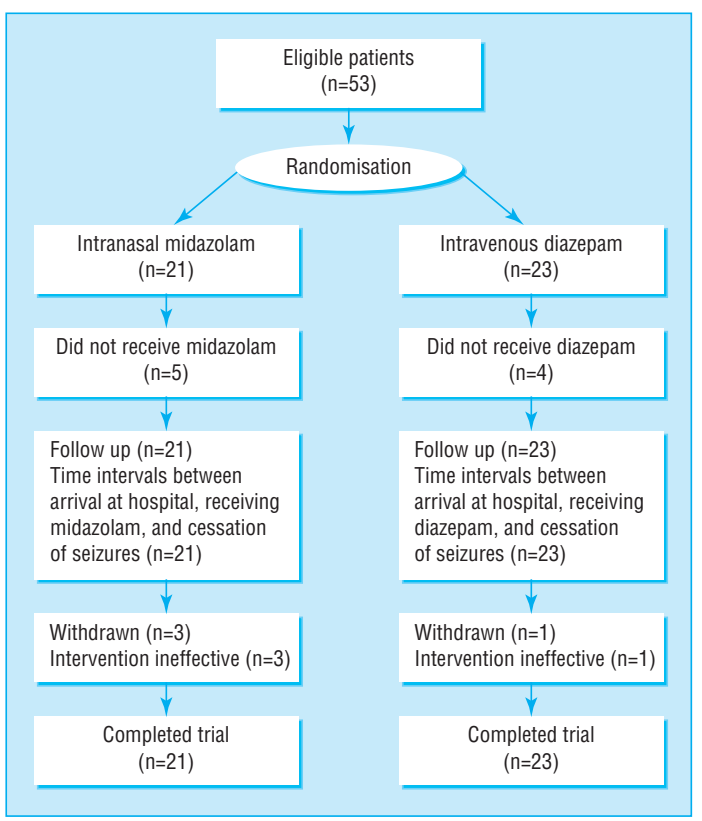

Fig 1 Flow of subjects through trial

three seizures in the midazolam group were controlled with intravenous diazepam and one with intravenous phenobarbital after intravenous diazepam failed. Two seizures in the diazepam group were controlled with intravenous phenobarbital. Statistically significant differences were found between the time of treatment and control of seizures. Time from arrival at hospital to treatment was faster in the midazolam group. Seizures were controlled faster in the diazepam group, and the time from arrival at hospital to control of seizure was faster in the midazolam group. Survival analysis showed a significant difference between the time to cessation of seizures after arrival at hospital in the two groups (fig 2). Two children with recurrent seizures, one in each group, failed to respond to midazolam and diazepam. Both were successfully controlled with intravenous phenobarbital.

None of the children had clinical signs of respiratory distress, bradycardia, or other side effects. Electrocardiograms, blood pressure, and the results of pulse oximetry were normal in all children during seizure activity and 60 minutes after cessation of seizures.

Table 1 Clinical characteristics of study groups. Values are numbers of children unless stated otherwise

\begin{tabular}{lcc} 
& $\begin{array}{c}\text { Intranasal } \\
\text { midazolam } \\
(\mathbf{n = 2 1 )}\end{array}$ & $\begin{array}{c}\text { Intravenous } \\
\text { diazepam } \\
(\mathbf{n = 2 3 )}\end{array}$ \\
\hline Median age (months) (range) & $16(6-38)$ & $18(6-40)$ \\
\hline Boys & 13 & 12 \\
\hline Girls & 8 & 11 \\
\hline Previous febrile seizures & 17 & 17 \\
\hline Recurrent febrile seizures & 4 & 6 \\
\hline Cause of febrile seizures: & 10 & \\
\hline Upper respiratory tract infection & 6 & 10 \\
\hline Acute otitis media & 3 & 4 \\
\hline Bronchopneumonia & 3 & 5 \\
\hline Clinical dysentry (shigellosis) & 4 & 3 \\
\hline Others & &
\end{tabular}




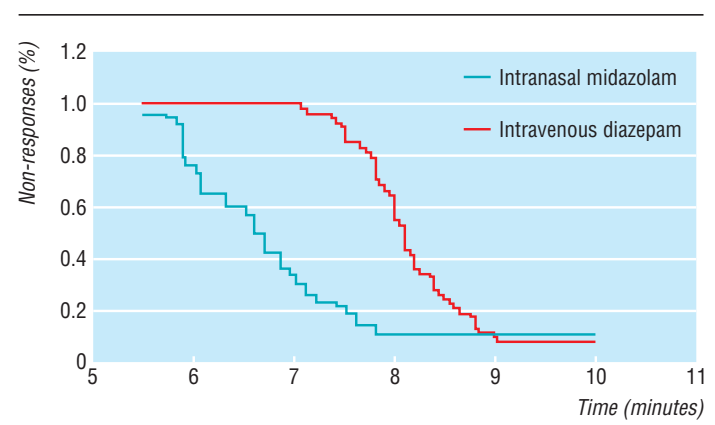

Fig 2 Time from arrival at hospital to cessation of seizures in children receiving intranasal midazolam $0.2 \mathrm{mg} / \mathrm{kg}$ or intravenous diazepam $0.3 \mathrm{mg} / \mathrm{kg}$, presented as survival data

\section{Discussion}

Midazolam given intranasally is as safe and effective as diazepam given intravenously in the management of febrile seizures in children. Midazolam, a 1,4benzodiazepine agent of the group of 1,2-unrelated benzodiazepines, is a water soluble compound. It has been extensively used in anaesthetic practice since 1982, and its pharmacology and pharmacokinetics are well known. ${ }^{16}$ The drug is hydrophilic at its prepared $\mathrm{pH}$ of 3.5 and is therefore reliably absorbed intramuscularly. At physiological $\mathrm{pH}$, its ring structure closes, it becomes highly lipophilic, readily crosses the bloodbrain barrier, and enters the central nervous system, with rapid clinical effects. ${ }^{17} 18$ The elimination half-life of midazolam is usually between 1.5 and 3.5 hours. ${ }^{16}$ Several studies have found it effective as an anticonvulsant-it inhibited convulsions in mice to a greater extent than diazepam. ${ }^{89}$ Midazolam given intramuscularly was effective in controlling convulsions in pigs, but its onset of action was not as fast as when given intravenously. ${ }^{19}$ The activity of interictal spike waves in adults with epilepsy was successfully abolished with intramuscular midazolam and intravenous diazepam. ${ }^{9}$

The safety and efficacy of midazolam has been shown by several clinical studies in epileptic adults and children, ${ }^{349}$ and continuous infusion of midazolam has successfully controlled status epilepticus in adults and children. ${ }^{20-22}$ Midazolam given intravenously or intramuscularly is not associated with respiratory changes, although there are reported associations with hypertension, bradycardia, and hypoxia in adults and children. These changes were, however, mild and transient. No patient had to be intubated or mechanically ventilated. ${ }^{22} 23$

As a result of the popularity of intranasal midazolam as a sedative agent for minor surgical interventions and diagnostic procedures, there is considerable information on its use in young children. The elimination half-life of intranasal midazolam at a dose of $0.2 \mathrm{mg} / \mathrm{kg}$ is similar to that when the drug is given intravenously, ${ }^{24}$ and no significant complications have been reported when it is given by the intranasal route. Therefore, it seemed pertinent to investigate the use of intranasal midazolam in the management of acute seizures, especially in children, where the introduction of an intravenous line is frequently unsuccessful.

One study found that intranasal midazolam given to epileptic children without clinical seizures (who were continuously monitored by electroencephalography) was absorbed rapidly through the nasal mucosa, and that it could suppress epileptic activity and improve the background for electroencephalography. ${ }^{14}$ None of the 19 children included in this study had apnoea or bradycardia.

We recently showed that intranasal midazolam is effective in the management of acute seizures in children. ${ }^{15}$ In 19 out of 20 children, control of seizures was achieved within 3.5 (SD 0.8) minutes of starting midazolam. None of the children had clinical signs of respiratory distress or bradycardia.

To our knowledge, no controlled studies have compared the efficacy of intranasal midazolam with intravenous diazepam for the management of febrile seizures. We found that seizures were controlled faster with intravenous diazepam than with intranasal midazolam but that midazolam was as safe and effective as diazepam. The time to cessation of seizure was shorter with intranasal midazolam.

A potential weakness of our definition of efficacy as being control of seizures under five minutes is the possibility of spontaneous cessation of seizures irrespective of treatment within this time. We attempted to minimise this limitation by choosing ongoing seizure for at least 10 minutes as our entry criterion to the study, assuming that the chance for spontaneous cessation of such prolonged seizures is low.

Although upper respiratory tract infection might help absorption by increasing blood flow to the nasal mucous membrane, the presence of nasal secretions could dilute the midazolam solution and interfere with its contact with the absorbing surface. Most of the children in our study had upper respiratory tract infections, but this only affected the absorption of midazolam and subsequent seizure control in three episodes.

Acute seizures have been treated with oral diazepam and lorazepam, sublingual lorazepam, rectal solutions of lorazepam and diazepam, and diazepam suppositories. ${ }^{25-28}$ Giving the drugs orally or sublingually is frequently difficult and hazardous when children are convulsing, and absorption of diazepam and lorazepam tablets and rectal lorazepam solution are relatively slow. ${ }^{29}$ Rectal diazepam can be given safely in a prehospital environment by medical and non-medical staff, as a means of providing immediate treatment for prolonged seizures. This may shorten the duration of seizures and simplify the management of these patients in the emergency department. ${ }^{5}$ Because our study was designed to investigate an alternative means of treating prolonged febrile seizures in an emergency setting, we chose to compare intranasal midazolam with intravenous rather than rectal diazepam, as the rectal route is not always reliable

Table 2 Duration of time intervals (in minutes) for giving drug, seizure control, and response to treatment in study groups. Values are means (SDs) and 95\% confidence intervals

\begin{tabular}{lll}
\hline Time to giving drug after arrival at hospital & Intranasal midazolam & Intravenous diazepam \\
\hline Time of cessation of seizure after giving drug & $3.5(1.8)(3.3$ to 3.7$)$ & $5.5(2.0)(5.3$ to 5.7$)$ \\
\hline Time to cessation of seizure after arrival at hospital & $3.1(2.2)(2.9$ to 3.3$)$ & $2.5(1.9)(2.4$ to 2.6$)$ \\
\hline P $<0.001$ for all groups. & $6.1(3.6)(6.3$ to 6.7$)$ & $8.0(4.1)(7.9$ to 8.3$)$ \\
\hline
\end{tabular}




\section{What is already known on this topic}

Midazolam given intranasally is a safe and effective treatment for prolonged febrile seizures in children

\section{What this study adds}

Control of seizures in children is faster with intravenous diazepam than with intranasal midazolam, but the time to cessation of seizures after arrival of a child at hospital is faster with intranasal midazolam

Intranasal midazolam may be used in general practice and, with appropriate instructions, by the parents of children with recurrent febrile seizures at home

owing to variable bioavailability and wide range of serum concentrations. ${ }^{30}{ }^{31}$ Rectal diazepam in the form of a gel was recently introduced as another effective and well tolerated treatment for acute repetitive seizures, which can be administered at home by trained caregivers. ${ }^{32}$

In conclusion, intranasal midazolam could be provided not only in medical centres but, with appropriate instruction, by the parents of children with febrile seizures at home. Further studies are, however, needed on a larger series of children with various types of seizures.

Contributors: EL had the original idea for, and coordinated, the study. MG, JB, and TB coordinated the study and helped with data analysis. MB helped with the analysis and, with EL, prepared the paper. EL will act as guarantor for the paper.

Funding: None.

Competing interests: None declared.

1 Hirtz DG. Generalized tonic-clonic and febrile seizures. Pediatr Clin North Am 1989;36:375-82.

2 Treatment of convulsive status epilepticus: recommendations of the Epilepsy Foundation of America's Working Group in status of epilepticus. JAMA 1993:270:854-49.

3 Chamberlain JM, Altieri MA, Futterman C, Young GM, Ochsenchlager DW, Waisman Y. A prospective, randomized study comparing intramuscular midazolam with intravenous diazepam for the treatment of seizures in children. Pediatr Emerg Care 1997;13:92-4.

4 Lahat E, Aladjem M, Eshel G, Bistritzer T, Katz Y. Midazolam in treatment of epileptic seizures. Pediatr Neurol 1992;8:215-6.

5 Alldredge BK, Wall DB, Ferriers DM. Effect of prehospital treatment on the outcome of status epilepticus in children. Pediatr Neurol $1995 ; 12: 213-6$

6 Siegler RS. The administration of rectal diazepam for acute management of seizures. J Emerg Med 1990;8:155-9.

7 Conner JT, Katz RL, Pagano RP, Graham CW. PO21-3981 for intravenous surgical pre-medication and induction of anesthesia. Anesthesiol Anal 1978:57:1-5.

8 De Jong RH, Bonin JD. Benzodiazepines protect mice from local anesthetic convulsions and death. Anesth Analg 1981;60:385-9.
9 Jawad S, Oxley J, Wilson J, Richens A. A pharmacodynamic evaluation of midazolam as an antiepileptic compound. J Neurol Neurosurg Psychiatr $1988 ; 49: 1050-4$

10 Latson LA, Cheatham JP, Gumbiner CH, Kugler JD, Danford DA, Hafschire PJ, et al. Midazolam nose drops for outpatient echocardiography sedation in infants. Am Heart J 1991;121:209-10.

11 Lacon A, Reddy VG. Nasal midazolam and ketamine for pediatric sedation during computerized tomography. Acta Anesthesiol Scand 1994;38:259-61.

12 Wilton NCT, Leight J, Rosen DR, Pandit U. Preanesthetic sedation of preschool children using intranasal midazolam. Anesthesiology 1988;69:972-5.

13 Saint-Maurice C, Landais A, Delleur MM, Esteve K, MacGee K, Murat I The use of midazolam in diagnostic and short surgical procedures in children. Acta Anesthesiol Scand 1990;94(suppl 92):39-41.

14 O'Regan ME, Brown JK, Clarke M. Nasal rather than rectal benzodiazepines in the management of acute childhood seizures? Develop Med Child Neurol 1996:38:1037-45.

15 Lahat E, Goldman M, Barr J, Eshel G, Berkovitch M. Intranasal midazolam for childhood seizures. Lancet 1998;352:620.

16 Dundee JW, Halliday NJ, Harper KW, Brogden RN. Midazolam: a review of its pharmacological properties and therapeutic use. Drugs 1984;24:519-43

17 Greenblatt DJ, Arendt RM, Abernethy DR, Giles HG, Sellers EM, Shader RI. In vitro quantitation of benzodiazepine lipophilicity: relation to in vivo distribution. BrJ Anaesthesiol 1983;55:985-9.

18 Arendt RM, Greenblatt DJ, de Jong RH, Bonin JD, Abernethy DR, Ehrenberg BL, et al. In vitro correlates of benzodiazepine cerebrospinal fluid uptake pharmacodynamic action and peripheral distribution.J Pharmacol. Exp Ther 1983;227:98-106.

19 Orebaugh SZ, Bradford SM. Intravenous vs intramuscular midazolam in treatment of chemically induced generalized seizures in swine. Am J Emerg Med 1994;12:284-7.

20 Galvin GM, Telinek GA. Midazolam: an effective intravenous agent for seizure control. Arch Emerg Med 1987;4:169-72.

21 Crisp CB, Gannon R, Knauft F. Continuous infusion of midazolam hydrochloride to control status epilepticus. Clin Pharmacol 1988;7:332-4.

22 Koul RL, Aithala GR, Chacko A, Yoshi R, Elbualy MS. Continuous midazolam infusion as treatment of status epilepticus. Arch Dis Child 1997;76:445-8.

23 Ghialin S, Van Ruckevorsel-Harmant K, Harmant J, Demersy TH. Midazolam in the treatment of epileptic seizures.J Neurol Neurosurg Psychiatry 1988;51:732-5.

24 Rey E, Delaunay G, Pons IM, Richard MO, Saint-Maurice C, Olive G. Pharmacokinetics of midazolam in children: comparative study of intranasal and intravenous administration. Eur J Clin Pharmacol 1991;41:355-7.

25 Scott RC, Neville BGR, Besag FMC, Boyd SG. Nasal rather than rectal benzodiazepines in the management of acute childhood seizures? [Letter.] Develop Med Child Neurol 1997;39:137-8.

26 Lombroso CT. Intermittent home treatment for status and clusters of seizures. Epilepsia 1989;30(suppl 2):11-4S.

27 Yager JY, Sestria SS. Sublingual lorazepam in childhood serial seizures. Am J Dis Child 1988;142:931-2.

28 Milligan NM, Dhillon S, Griffiths A, Oxley J, Richens A. A clinical trial of single dose rectal and oral administration of diazepam for the prevention of serial seizures in adult epileptic patients. J Neurol Neurosurg Psychiatry $1984 ; 47: 235-40$

29 Dhillon S, Oxley J, Richens A. Bioavailability of rectally administered lorazepan. Br J Clin Pharmacol 1982;13:427-32.

30 Remy C, Jourdil N, Villemain D, Favel P, Genton P. Intrarectal diazepam in epileptic adults. Epilepsia 1992;33:353-8.

31 Magnussen I, Oxlund HRW, Alsbirk KE, Arnold E. Absorption of diazepam in men following rectal and parenteral administration. Acta Pharmacol Toxicol 1979;45:87-90.

32 Dreifuss FF, Rosman NP, Cloyd JC, Pharm D, Pellock JM, Kuzniecky RI, et al. A comparison of rectal diazepam gel and placebo for acute repetitive seizures. N Engl J Med 1998;338:1869-75.

(15 March 2000)

\section{Email submissions from outside the United Kingdom}

We are now offering an email submission service for authors from outside the UK. The address is papers@bmj.com Ideally our email server would link seamlessly with our manuscript tracking system, but for now it does not, which is why we are offering the service only to authors outside the UK Most post in the UK arrives the next day, so UK authors have the least to gain in speed of delivery from email delivery. As soon as our systems improve we will invite email submissions from everyone.

If you choose to send your submission by email please would you send the text and any tables and figures as attached files, together with a covering letter giving all your contact details (postal address, phone, fax, and email address). We can read files created with most word processing, graphics, and spreadsheet programs.

When your submission is received in our email box you will receive an automatic acknowledgment to show that it has arrived. If the submission is incomplete we will contact you and ask you to resend the missing information.

Once the submission is complete we will register it on our manuscript tracking system and you will receive a standard acknowledgment in the post.

Letters to the editor should continue to be sent direct to bmj.com as rapid responsesor toletters@bmj.com 